Pre-publication. IN: Al Approaches to the Complexity of Legal Systems. Pompeu Casanovas, Ugo Pagallo, Monica Palmirani, Giovanni Sartor (Eds.), Springer, The Netherlands, 2014, pp 247-260. Final publication available at Springer

http://link.springer.com/chapter/10.1007\%2F978-3-662-45960-7_18

\title{
CONSUMEDIA. Functionalities, emotion detection and automation of services in a ODR Platform."
}

\author{
Josep Suquet ${ }^{\mathrm{a}}$, Pompeu Casanovas $^{\mathrm{b}}$, Xavier Binefa $^{\mathrm{c}}$, Oriol Martínez ${ }^{\mathrm{d},}$ Adrià Ruiz ${ }^{\mathrm{e}}$ \\ Jordi Ceballos ${ }^{\mathrm{f}}$
}

a,b UAB Institute of Law and Technology, Law Faculty, Universitat Autònoma de Barcelona, Cerdanyola del Vallès, 08193 Barcelona, Spain

c,d,e Department of Information and Communication Technologies, Universitat Pompeu Fabra, Tànger St. ,122-140,08018 Barcelona, Spain

f, ICA, Informática y Comunicaciones Avanzadas, C/Almogàvers, 107- 119, 08018 Barcelona, Spain, jordi.ceballos@grupoica.com

\{josep.suquet, pompeu.casanovas\}@uab.cat, \{xavier.binefa, oriol.martinez, adria.ruiz\}@upf.edu, jordi.ceballos@grupoica.com

\begin{abstract}
This paper presents a legal and technological approach to online mediation. It shows the technologies that are usually employed in this field and presents the prototype of Consumedia, an online mediation platform, as well as its functionalities and technological architecture. Moreover, it uncovers the technology implemented as regards the recognition of emotions in the mediation room. Furthermore, it considers that an online mediation platform may automatically provide the parties with all the required documentation of the process. Thus, it unveils the documents that an online mediation platform should automatically provide to the disputants.
\end{abstract}

Keywords: Online mediation, ODR, emotion detection, ontologies, automation, documents, phases, B2B, B2C.

\footnotetext{
* P. Casanovas et al. (ed.). AI Approaches to the Complexity of Legal Systems. Springer Berlin Heidelberg, LNCS, 8929, 2014. 247-260.
} 


\section{Introduction: the regulatory framework}

Alternative Dispute Resolution (ADR) refers to out-of-court mechanisms of redress and usually includes negotiation, mediation, recommendation and arbitration. Mediation is a relational justice mechanism, because the parties who suffer a conflict are empowered so that they may solve it by themselves through a collaborative conduct [1]. Accordingly, mediation is a structured process whereby a third impartial party assists the contending parties without imposing or proposing a solution to the conflict, but puts his efforts in bringing the parties together in order to solve the conflict by themselves.

Mediation may be undertaken as a conflict resolution mechanism in a wide array of domains, such as business-to-consumers disputes (B2C), business-to-business disputes (B2B), family law, labor law, etc. Yet, mediation mechanisms should be fostered for low-value disputes because this may be the only available option for redress. Indeed, European surveys show that the access to courts is usually too complex and costly for low-value disputes and consequently very few European consumers bring a conflict to a court [2]. To allow reaching solutions as regards this type of controversies, mediation procedures in this field should be kept as simple as possible. For instance, consumer conflicts are usually of a similar nature involving many consumers against few traders arising in certain domains such as air transport (conflicts with air companies), telecom/telephony and utilities [3].

It has been said that this field is particularly suitable for the introduction of Information and Communication Technologies (ICT) and fully supports automated mediation procedures because the similarity of conflicts may enable mediation providers to standardize a great deal the treatment of information in the consumer redress arena [3]. This process may be facilitated through the use of ICT, which may be principally devoted to facilitating the communication between the parties and the management of the process.

Online Dispute Resolution (ODR) is usually understood as any ADR mechanism in which ICT play a significant role [4]. Today, the areas of both ADR and ODR are very active. On the one hand, the ODR academic community is developing both a theoretical and practical approach towards ODR [5]. On the other hand, the legislative authorities are fostering the use of ITC in the dispute resolution domain. In the consumer domain, the European institutions have enshrined two main legal instruments that will probably pose ADR and ODR in the centre of the consumer redress debate in the next decades.

On the one hand, the Directive 2013/11/EU (Directive on consumer ADR) will provide a common regime in the EU for consensual, advisory and determinative ADR mechanisms. This Directive has supposed a shift in the EU approach: While the EC Directive on mediation in civil and commercial matters applies to mediation processes only, the Directive on consumer ADR is devoted to applying to adjudication and recommendation services as well as mediation services. On the other hand, the EU 
Regulation 2013/524 on consumer ODR is intended to create an online platform. ${ }^{\dagger}$ This could develop into an interactive website offering a single point of access to consumers and traders who seek to resolve their dispute out-of-court for cross-border e-commerce transactions.

Act 5/2012 of 5 July, of mediation in Civil and Commercial Maters is the legislative instrument that transposes the EC Directive on Mediation in Spain. ${ }^{\ddagger}$ This entitles the parties to conduct partly or totally mediations online. Indeed, party autonomy is recognized as it sets out that parties may agree that all or some of the acts of mediation are carried out electronically, by videoconference or other similar means of transmission of the voice or image, provided that the identity of the participants and the respect for the principles of mediation are guaranteed (article 24.1). Moreover, it establishes that a mediation process consisting of a claim not exceeding $600 €$ shall be developed preferably by electronic means, unless its use is not possible for either party (article 24.2).

Furthermore, Act 5/2012 mandates the Government to develop an online simplified mediation procedure for disputes involving purely claims for payment (Final Disposition 7). This procedure is mandated to last no more than a month, although this period may be extended by agreement of the parties. Accordingly, the Spanish legislation will enshrine two different online mediation procedures: a general procedure and a simplified procedure for low-value complaints. Very recently, a new regulatory instrument, the Royal Decree 980/2013, has set up the simplified online mediation procedure. ${ }^{\S}$

After these introductory remarks, the following section briefly describes some of the technologies that may be used in online mediations today. Then, section 3 presents the functionalities and the architecture of Consumedia, a pilot online mediation platform. Section 4 unveils the implementation of an automatic facial expression recognition mechanism that may help overcome the loss of information in comparison to inperson mediations. This may help the mediator understand the emotions of the parties and provide a better tool as to his tasks to assist the parties. Then, section 5 considers further aspects that can be automated in a platform and focuses on the documentation that an online mediation platform could automatically provide to the parties. Since this is an aspect that may be regulated by the Law, section 5.2 analyses the Spanish legislation regarding civil and commercial mediation. Finally, section 6 provides some conclusions.

Both legislative instruments are published in OJEU, L 165/63, of 18 June 2013.

Ley 5/2012, de 6 de julio, de mediación en asuntos civiles y mercantiles (Published in BOE num. 162, of 7 July 2012).

$\S$ Real Decreto 980/2013, de 13 de diciembre, por el que se desarrollan determinados aspectos de la Ley 5/2013, de 6 de julio, de mediación en asuntos civiles y mercantiels (Published in BOE num. 310, of 27 December 2013). 


\section{Technologies for online mediation}

Many technologies can be used in the context of online mediation procedures or other methods of ODR. Some technologies may, though, be specifically indicated to support the mediation process, and may be addressed to support the process itself or to support the parties of the process [4]. In the first case, the technology is dedicated to the administration of the process in order to guarantee a smooth running of it. For example, it can enable the automatic flow monitoring of the process, controlling the sequence of the process, the timing and the participation of the parties, or it may register the cases, performing a digital transcript of them. In addition, the technology can structure information like the claim request, offer, counteroffer or final agreement, particularly through electronic forms.

Technology can also help the parties decide what to do about the process, in particular, by assisting them in the formulation of their positions. Yet, technology can also provide a substitute tool for the parties. In fact, this is a fertile field for the implementation of new tools and methodologies for the automatic resolution of complaints. The so-called Agreement Technologies (Agreement Technologies, AT) ${ }^{* *}$ is a new area of research that aims to discuss the theory and practice of computer systems in which agents negotiate and take agreements on behalf of human users [6]. Furthermore, Negotiation and Decision Support Services (NDSS) can assist the parties in formulating their positions and quantifying different aspects of the dispute. Here, Family Winner and Asset Divider are two most remarkable, interest-based, computer programs developed in the field of family law in Australia. They attribute the conflicting items at stake to each of the parties according to the evaluation that each party has performed $[7,8]$.

Technology can also help create automated negotiation, blind-bidding services, which may be complementary or substitutive to online mediation processes. In these cases, the parties agree that their pecuniary dispute can be solved by the use of a software device. The parties who have an economic dispute agree on an economic margin (e.g., $1000 €$ ) and make a few rounds of confidential negotiations with different confidential bids. If the parties fail to agree on an economic margin, the software does not communicate to the other party the various economic amounts. If the parties' bid fall within the margin, the software solves the controversy by diving the margin between the parties. Thus, if party A offers 900 and party B requests 1,000 and the parties have previously established a margin of 100 , the system resolves the dispute by dividing

\footnotetext{
** Cfr. http://www.agreement-technologies.org/: "the scientific research in the area of agreement mechanisms for virtual societies is a recent discipline oriented to increase the reliability and performance of electronic communities by introducing in such communities these well known human social control mechanisms. Computer science has moved from the paradigm of an isolated machine to the paradigm of a network of systems and of distributed computing. Likewise, artificial intelligence is quickly moving from the paradigm of an isolated and non-situated intelligence to the paradigm of situated, social and collective intelligence."
} 
the net and subtracting it with equal parts: A will pay 950 and B will receive 950 . In these cases, the technology presents a determinative role [9].

Mediation technologies can assist both the mediator and the parties to the dispute and can also be classified as communication technologies and case management technologies. Communication technologies can assist them with basic communication tools such as emails or SMS, whereas other technologies can enhance the creative process with 2.0 tools such as wikis or virtual maps of the conflict. In addition, there are other cases in which the technology enables the mediation process to be conducted online [4]. The most sophisticated cases are online mediation platforms. These may include synchronous tools such as video conferencing or audio conferencing, instant messaging or chats or asynchronous tools such as email, discussion forums, online forms, or electronic boards. The following paragraphs precisely show a prototype of one of these mediation platforms, in which the authors have been devoting their efforts in the lasts years, and the functionalities implemented.

\section{Consumedia: a user case}

Consumedia is a research project funded by the Spanish Ministry of Science and Innovation, which aims at implementing an online mediation platform for both $\mathrm{B} 2 \mathrm{C}$ and B2B disputes. The Consumedia project is a follow-up of other research projects such as Ontomedia $[20,21]$ and, specifically, the White Book of Mediation in Catalonia $(\text { WBMC })^{\dagger \dagger}$. The WBMC was an in-depth research project funded by the Government of Catalonia which aimed at analyzing mediation as a means of redress in a widearray of areas such as B2C, B2B, family, labor or healthcare, and to assess the degree of implementation of mediation in Catalonia. The WBMC has proved to be a very fertile environment for knowledge acquisition. In particular, one of the chapters was devoted to technologies and mediation ([4] and a prototype of a online mediation platform was created [9]. Accordingly, the WBMC considered that mediations could also take benefit from the implementation of ICT, and it recommended "the promotion and implementation of online mediation (ODR) in the various fields of mediation, significantly in areas such as in Consumer Law (...)" [10].

The Consumedia platform is shown in figure 1. The platform provides both asynchronous and synchronous communication tools, with text-based and audio-visual facilities. The online mediation platform implements electronic messaging and a public and a private chat. It also provides an electronic board where parties can write any eventual arguments or drawings. Moreover, it contains a mediation room with a videoconference facility. This shows both the claimant and the respondent, which are horizontally placed on the top of the screen; the mediator is displayed underneath. In addition, one of the technological tools derives from the use of automatic facial expression detection, as it is further explained in section 4 . The platform also provides back-office facilities such as a repository of pending and current mediation cases, a

\footnotetext{
${ }^{\dagger \dagger}$ http://www.llibreblancmediacio.com
} 
historical database of mediation processes already conducted, and the description of the different cases. Figure 2 shows the different use cases, and which user profiles can access each of them.

\section{consumedia}

Legal | Contacto I Español v

$$
\text { Más información }
$$

\section{¿Qué es Consumedia?}

Es una plataforma de resolución de conflictos online que sirve como canal de comunicación entre varias partes de un conflicto, las diversas instituciones encargadas de llevar a cabo la administración del conflicto asi como las terceras personas imparciales y neutrales (mediadores) encargadas de la resolución del conflicto.
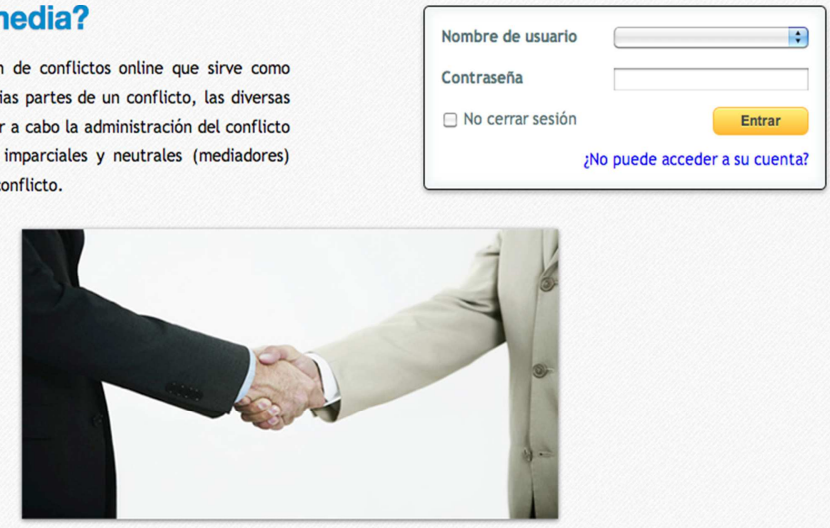

Fig. 1. Consumedia's online mediation platform

\begin{tabular}{|l|c|c|c|}
\hline \multicolumn{1}{|c|}{ Use case } & Administrator & Mediator & Claimant/Respondent \\
\hline To appoint a mediator to a new case & $\mathrm{X}$ & & \\
\hline To create, modify or delete a mediation case & $\mathrm{X}$ & $\mathrm{X}$ & \\
\hline To accept the appointment of a new case to a mediator & & $\mathrm{X}$ & \\
\hline To reject the appointment of a new case to a mediator & & $\mathrm{X}$ & \\
\hline To change the current phase of mediation & & $\mathrm{X}$ & \\
\hline To edit private notes in a mediation case & & $\mathrm{X}$ & $\mathrm{X}$ \\
\hline To manage shared documents in a mediation case & & $\mathrm{X}$ & $\mathrm{X}$ \\
\hline To manage mediation rooms with videoconference facilities & & $\mathrm{X}$ & \\
\hline To make a videoconference call & & $\mathrm{X}$ & $\mathrm{X}$ \\
\hline To visualize a videoconference already made & & $\mathrm{X}$ & \\
\hline $\begin{array}{l}\text { To browse emotion automatic recognition in a videoconference } \\
\text { already made }\end{array}$ & & $\mathrm{X}$ & \\
\hline $\begin{array}{l}\text { To check text from automatic audio transcription of a } \\
\text { videoconference already made }\end{array}$ & & & $\mathrm{X}$ \\
\hline To create a new claim & & & \\
\hline
\end{tabular}

Fig. 2. Use case and user profiles

The technical architecture of the application is shown in the figure 3. The layers of the software architecture are based on ontologies and semantics, multimedia analysis and the mediation platform.

- Ontologies and semantics: Set of ontologies for online mediation that allow semantic search according to mediation databases. 
- Multimedia analysis: Set of multimedia processes that offer the following advanced features.

- Emotion recognition from automatic analysis of real-time video.

- Speech analysis, which can detect the language used by each partner, and automatically transform the corresponding audio transcription into text.

- Visual browsing based in a timeline, which permits to visualize a videoconference already made, the content of the chat and the recognition of emotions.

- Mediation platform: It consists of a web application where users can access and which consists of the following components:

○ PostgreSQL database where all the information managed by the application is stored. It is a free and open source database, which does not require the payment of use licenses in a business environment.

- Storage of audios and videos on a file system.

○ Portal developed under the LifeRay Java platform, which allows the creation of different security profiles, which are the administrator, mediator and claimant/respondent.

○ Videoconferencing system developed with Red5 Media Server, and customized to the needs of the project.

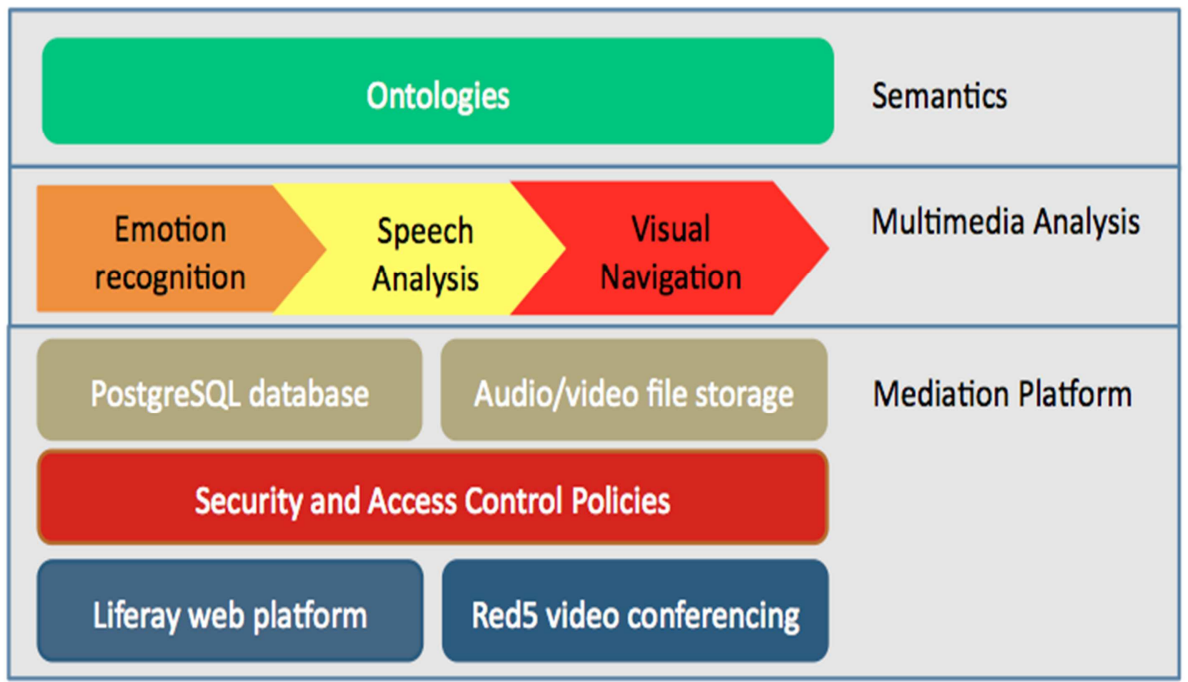

Fig. 3. Architecture of Consumedia

\section{Emotion detection in Consumedia}

Communication processes over online platforms (such as chat, e-mail, videoconference or even virtual worlds) have been extensively studied, specifically for online education platforms. One of their main drawbacks is the amount of information 
that it is lost in comparison with in-person communication processes. For instance, in the context of online learning platforms, it has been shown to decrease student connectivity, engagement and retention [11]. However, other studies have shown the intensifying power of emotions when the attention keep focused on specific topics in which humans feel involved [22]. Given that the face is one of the main human nonverbal communication channels, the analysis of the set of facial gestures performed by a subject in a given situation can be used to improve the viewer perception of the communication process. This can partially mitigate the loss of information in computer-mediated communications.

In an online mediation, where the communication process takes place in a videoconference room, emotion analysis through facial expressions detection and classification can be used to highlight or summarize the affective events that occur in the communication process, providing tools to the mediator to improve its management.

\subsection{Automatic Facial Expression Recognition}

In his earlier psychological studies [12], Paul Ekman showed that there are six universal facial expressions that share the same meaning across all human cultures. The facial expressions defined by Ekman were: disgust, fear, happiness, surprise, sadness and angry. As we have explained, the automatic detection of these prototypical facial expressions can provide very useful information to index, summarize or understand an online mediation process.

In the last decade, automatic detection of facial expressions have been attracted a lot of interest from the computer vision community. Many efforts have focused on proposing systems that are able to detect the six universal facial expressions in images or videos. Usually, these systems follow the pipeline illustrated in Figure 4.

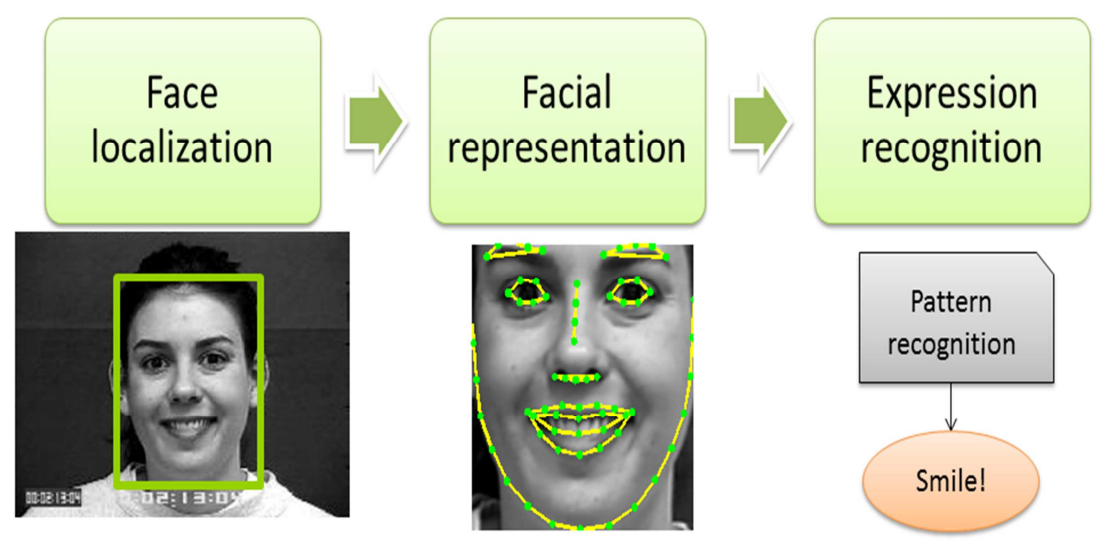

Fig. 4. Pipeline overview of an automatic facial expression recognition system 
Given an image, we firstly need to locate where the face is. For this purpose, we can use methods such as the Viola \& Jones algorithm [13] implemented in most of modern digital cameras. Once spotted, a numerical representation of the face can be extracted. This representation encodes the information. For instance, we can automatically obtain the location of different facial landmark points (eyes, mouth borders, nose, eyebrows...) and use their coordinates in the image as a facial representation. Finally, pattern recognition models are applied over these representations in order to recognize which facial expression occurs in the image of the performing subject.

For the Consumedia platform, we have used the method proposed in [14] to automatically detect the six universal expressions described above. This method follows a similar pipeline to detect facial expressions. Given a frame from a subject recorded during a mediation process, a set of 66 facial landmark points are extracted using the method proposed in [15]. Then, regression techniques are used in order to map the coordinates of all points into a number from 0 to 1 denoting the intensity of each facial expression. These regression models are trained with the CK+ Facial Expression Database [16]. For more technical details, the reader is referred to the original paper. Figure 5 shows a typical result obtained applying this method.

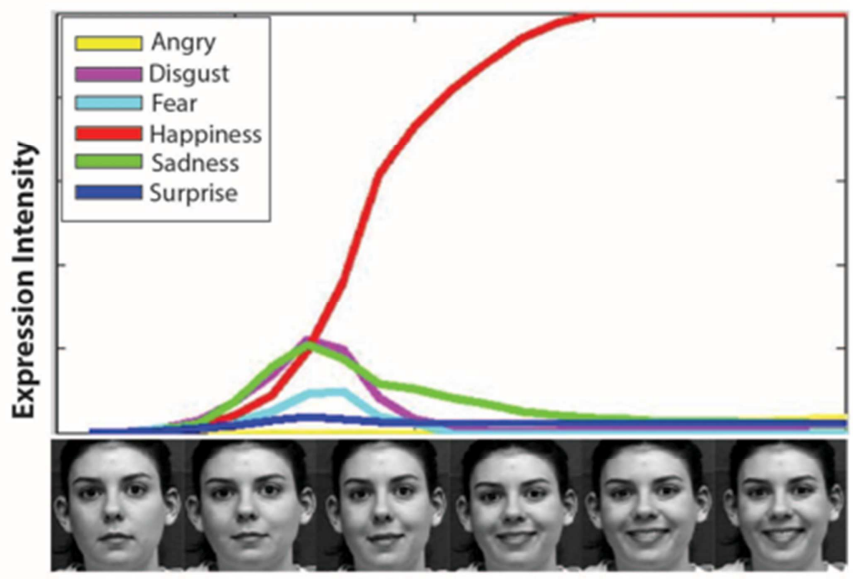

Video Frames

Fig. 5. Result after applying the method in [15] to a video containing a smiling subject. Each colored line represents the estimated intensity of each given facial expression along a sequence.

\subsection{Use of the facial expression information in the Consumedia platform}

The Consumedia platform offers a mediation room with a videoconference facility (see Figure 6) that besides the mediation task also records and analyses the audiovisual streams of the claimant and the respondent. The analysis involves the facial expression recognition system, and an automatic voice transcription system as well.

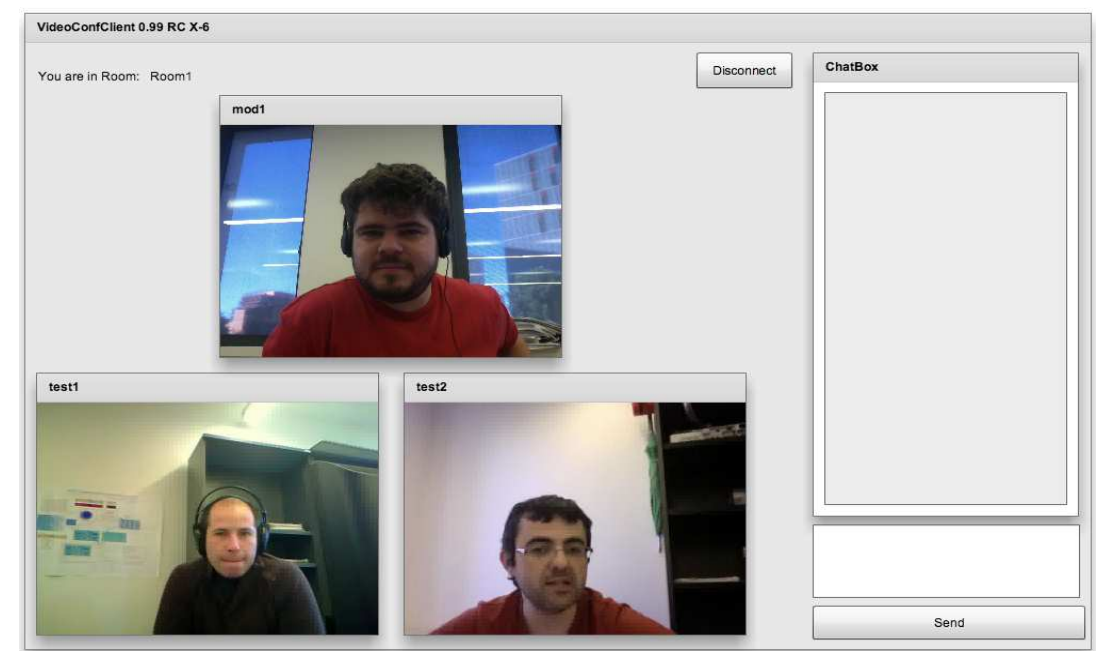


Fig. 6 Videoconference room provided in the Consumedia platform. On the left, windows where the claimant, the respondent and the mediator (on top) are visualized.

The information obtained through this kind of analysis can be applied to summarize the mediation process. For instance, in the Consumedia platform, it is used to indexing and also navigating the multimedia content gathered from the videoconference facility. Navigation trough the recorded contents can be enhanced using a colored bar, in which each color represents a specific emotional state.

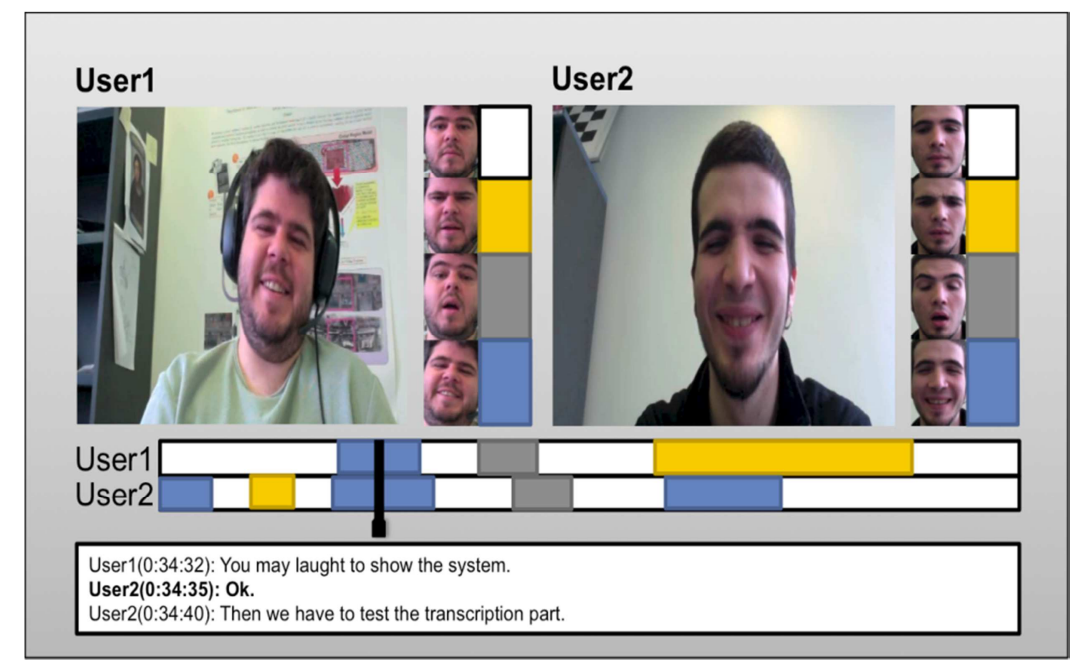

Fig. 7 Prototype for offline navigation along the videoconference content using facial expression information analysis. The black line over the bar indicates an instance of time and it is used to navigate through the recorded content.

\section{A further step towards the automation of services}

\subsection{Ontologies in online mediation procedures}

Mediation is a technique that may be developed according to a diversity of processes and procedures that may vary from the specific field in which it is conducted. As it was stated by the conclusions and recommendations of the WBMC [10]:

“(...) mediation is composed of different processes with different protocols depending on the sector. There is a common goal though: getting to a more reasonable option before going to litigation or before the conflict becomes socially unmanageable."

The Law may regulate some of the aspects of the process, detail the phases (e.g., pre-mediation, mediation and post-mediation phases) or, instead, the flowchart of the 
process may be left it for the autonomy of the mediation provider. The WBMC recommends the implementation of ICT in mediation processes, but it warns about the importance of implementing protocols and the standardization of processes before any tool is built. As it states:

"Only those (procedures) having more simply and defined stages and objects are good starting points for the elaboration of automated protocols beyond the use of telephone, e-mail and websites" [10].

The online mediation proceedings entail heterogeneous actions from the parties (claimant and requested party) as well as from the mediator (third party) and the mediation provider. These actions may include a request for mediation, a request for conducting a mediation process online, an answer from the requested party to enter into a mediation process, or a request for a suspension of a mediation process. The mediator or the mediation provider may also require the parties to inform about several aspects, such as to correct eventual errors or omissions in the mediation request.

In this landscape, ontologies may play a central role. As it has been said, ontologies are especially suitable for the automation of some parts of the process and they have proved useful in modeling legal knowledge [17]. They well may be used in both the e-justice and ODR domains. Indeed, ontologies have been defined as a formal, explicit specification of a shared conceptualization. This means that ontologies are machine-readable, abstract models in which the type of concepts used and the constraints on their use are consensual knowledge and explicitly defined [18]. Accordingly, ontologies may be implemented in an online mediation platform for the automation of several aspects of the proceedings, such as the following:

i) The assignment of a given ODR/ADR provider and a mediator from the text of the claims made by the consumer claimant. From the consumer complaint expressed in natural language, an ontology might appoint a specific mediator and a provider to a new case. In this case, different "tag" words may serve to identify a provider or a mediator. In particular, one of the most useful cases can be attributing a conflict to either a B2C or a B2B entity. The functionality here, would be based on keywords to assign the case to one or the other domain (e.g, words such as "consumption", "journey", "phone", "gas", "light", "electricity", "airplane ticket", could be words usually associated with a consumer relationship). However, this may only be a guide to assign a case to an ODR provider, which must subsequently ensure that the assignment was actually correct.

ii) To provide the applicable law to the relationship involved. Similarly to the former case, from the claim made by the claimant, an ontology might help detail the applicable legislation. There may be some words such as "car, vehicle, car repair shop," that would be assigned to some legal instruments (such as the Spanish Royal Decree 1457/1986, of 10 January, on the industrial and service delivery in the vehicle repair shops, or Law 40/2002, of 14 November, regulating the parking of vehicles). Moreover, using the words "trip cancellation, flight, passenger boarding, denial, delay, accident, airline" the search engine could provide information on applicable legal instruments such as Regulation 261/2004 of 11 February 2004, that establishes common rules on compensation and assistance to air passengers or Regulation 2027/97, 
on air carrier liability in respect of the carriage of passengers and their baggage by air, to name only a few.

iii) An ontology may also be implemented so that it can automatically provide to the parties with the documentation required in each phase of the mediation process. This requires defining all the phases and deadlines of the mediation process, and correspondingly to implement a protocol of mediation. The following paragraphs focus on this aspect. They study the legislation of mediation in civil and commercial aspects and ascertain the different phases that may be subject to those domains. The final goal is to show what documents should, an automated platform consider in a mediation process.

\subsection{Automated mediation process: actions and documents}

The Spanish Act 5/2012, on civil and commercial mediation establishes some phases that the parties and the mediator must observe when conducting a mediation process. The following phases should also be maintained in online mediation proceedings. These phases encompass an initial and informative session (Article 17) as well as a constitutive session, the last one being incorporated into a formal act that has to be manually or digitally signed by the parties and the mediator (Article 19.2). Moreover, the parties may undertake several mediation sessions such as private mediation sessions (also named caucus) or joint mediation sessions. Furthermore, according to this legislative instrument, the procedure ends with a final act that will determine its conclusion and, where appropriate, reflect the agreements reached in a clear and understandable way; or, alternatively, its termination for any other reason (Article 22.3). The Law also sets out that the parties and the mediator must manually or digitally sign the final act and that one copy shall be given to the parties.

In order to be able to develop an ontology that could automatically provide the parties with all necessary information documents that should be exchanged between the parties and the mediator, a thorough analysis of Act 5/2012 and the regulation that develops this instrument (RD 980/2013) has been undertaken. It should be noted that the latter legal instrument sets out a simplified online mediation procedure but a general online mediation procedure is still not regulated. According to this study, the online mediation platform should provide the parties with a wide array of documentation included in the different actions that the parties and the mediator may perform in the mediation proceedings. This documentation should be available in a clear, readable and in a standardized way.

The following figure shows the actions that should be allowed by the diverse documents uploaded into the platform. 


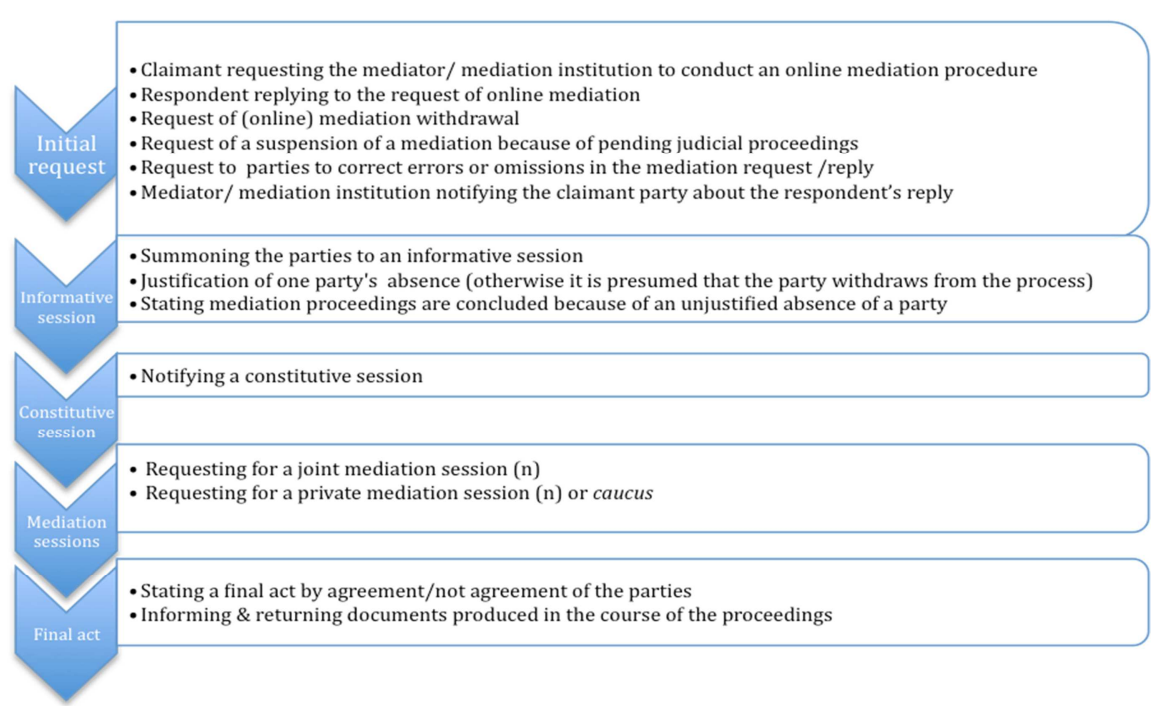

Fig. 8 Actions by phases in a general online mediation process.

Furthermore, one of the novelties of Act 5/2012 and, subsequently, RD 980/2013 is the possibility to create simplified online mediation procedures for low-value, pecuniary disputes that must not last more than a month. In such cases, the documentation should be simplified. Even if the phases of the mediation process (Informative session, constitutive, mediation sessions and terminative sessions) should be followed, the RD 980/2013 is not clear about how these sessions should be conducted. In any case, this scheme creates a software assisted negotiation mechanism, rather than an online mediation process, because it allows the parties to make different offers and counteroffers, assisted by the technology, until they agree or not on a solution. The economic quantity that the claimant claims and the quantity that the respondent is willing to accept are to be offered through simple online forms.

The simplified online mediation procedure begins with an initial mediation request. Then, the mediator contacts the respondent and asks him or her whether he or she accepts entering into the process. The mediator may also require both parties to correct omissions or mistakes in both the request form and the reply form. After the respondent replies accepting to enter into the simplified process, the mediator will provide the parties with a document certifying the constitutive session, generating a file number and determining the beginning of the proceedings (art. 37 RD 980/2013). Moreover, the mediator should provide a document certifying proceedings are properly conducted, with the number of registry, date and time of presentation, identity of mediation and of the mediation institution (art. 34 RD 980/2013). Finally, the mediator or the mediation institution should also provide a document containing the agreement or the lack of agreement, and which has the value of a final act. According to this, the platform should provide several standard documents to the parties, shown in figure 9 . 


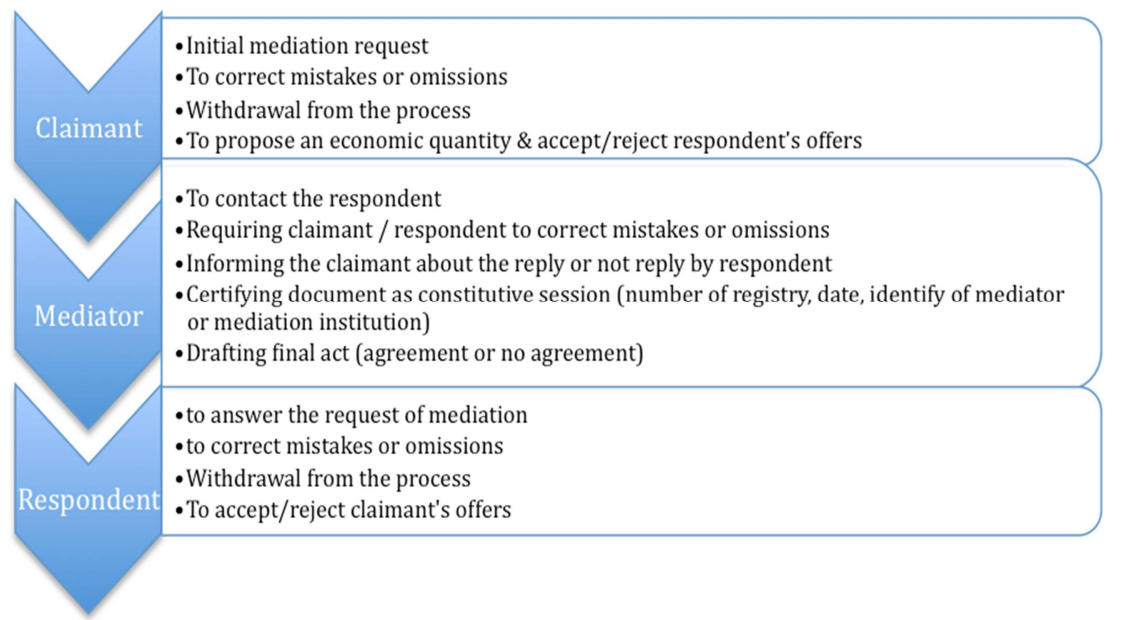

Fig. 9 List of actions to be undertaken by standard forms in a simplified online mediation procedure (according to each party).

\section{Conclusions and further work}

Mediation is a structured process whereby a third impartial party assists the contending parties without imposing or proposing a solution to the conflict. The mediator puts his efforts in bringing the parties together so that they can solve the conflict by themselves. This process may be facilitated through the use of ICT, which can be devoted to facilitating the communication between the parties and the management of the process. This has been named the "fourth" party in the dispute, because ODR assistance sets and independent framework for the dispute be solved [23].

A. Lodder [24] and Lodder and Zeleznikow [25] have recently shown the need to take into account a "fith" additional party — the technology provider. This means that singling out who is providing the platform, and who is taking the responsibility for the overall mediation processes which have to be run onto it, matters. In the case of Consumedia, the fifth party is not only the consortium (I+D) who is constructing the tools, but the Council of the Chambers of Commerce of Catalonia as well. In principle, the platform will be used to provide an ODR B2B mediation service, depending on the Council. Therefore, the Council's mediators and representatives have been involved in the knowledge acquisition process, the definition of functionalities, and the walkthrough testing since the very beginning. This intended prudence, seeking fairness and the "sense of reality" in the construction of computing tools, is encompassed as well by the present trends on AI and ODR [26].

Online mediation platforms can enable the parties to conduct a mediation process semi-automatically. For one thing, Consumedia stays in a classical way to implement such processes, for that it offers an electronic messaging system, along with a public and a private chat. It also provides an electronic board where parties can write any 
eventual arguments or drawings, with a mediation room and a videoconference facility.

One of the most innovative aspects derives from the use in the mediation room of an Automatic Facial Expression Recognition system. Here, the system records and analyses the audio-visual streams that belong to the claimant and the respondent, both in terms of facial expression recognition as well as voice transcription. For privacy and data protection compliance, the metadata are recorded and can be just visualized and used only by the mediator, and only for professional purposes, to recall the case and improve her performance.

Yet, in the search for a fully automated mediation process this paper considers a further step. Here, one of the functionalities of an online mediation platform can be to automatically provide the parties with all the necessary procedural documents that the Law might require. Foreseeing all the necessary information activities between the parties of the process (claimant and respondent), as well as the mediator and the mediation institution, is not an easy task. In order to do that, the work of legal and computer scholars lean on the analysis of the applicable legislation to standardize and restructure the legal knowledge [19]. It could ultimately determine the diverse documents that should be uploaded into the platform.

This study analyses Act 5/2012, regulating civil and commercial mediation in Spain and its Royal Decree 980/2013, regulating a simplified online procedure for claims for payment. The latter instrument also provides for an assisted negotiation mechanism. The analyses of these diverse instruments serve to identify, structure and prepare the actions and the documents that the Consumedia platform should upload when implementing fully automated online mediation services, in the next future. This will be checked too at the benchmark (with selected cases) in the upcoming testing phase of the project.

Acknowledgements. Consumedia: ontology-based platform for the modeling of business and consumer mediation processes, financed by the Spanish Ministry of Science and Innovation (IPT-2011-1015-430000), and CROWDSOURCING: Semantic tools for the development of online participation and mediation, financed by the Spanish Ministry of Economy and Competitiveness (DER 2012- 39492 -C02 -01).

\section{References}

1. Casanovas, P., Poblet, M.: Concepts and Fields of Relational Justice. In: P. Casanovas, G. Sartor, N. Casellas, \& R. Rossella (Eds.), Computable Models of the Law, Berlin- Heidelberg, Springer Verlag (2008)

2. European Commission: Consumer attitudes towards cross-border trade and consumer protection. Analytical report. (Flash Eurobarometer) (European Commission EB Series 358, (2013)

3. Barral Viñals, I., Suquet Capdevila, J.: La mediación en el ámbito de consumo. In: Casanovas, P., Magre, J., Lauroba, $M^{a}$ E. (eds.), Libro Blanco de la Mediación en Cataluña, pp.301-370, Departament de Justícia, Generalitat de Catalunya, Huygens, Barcelona (2011) http://www.llibreblancmediacio.com/ 
4. Poblet, M., Noriega, P., Suquet, J., Gabarró, S., Redorta, J.: Tecnologías para la mediación en línea, estado del arte, usos y propuestas. In: Casanovas, P., Magre, J., Lauroba, M. E. (eds.), Libro Blanco de la Mediación en Catalunya, pp. 943-985, Departament de Justícia, Generalitat de Catalunya, Huygens, Barcelona (2011), http://www.llibreblancmediacio.com/

5. Abdel Wahab, M. S., Katsh, E., \& Rainey, D.: Online Dispute Resolution: Theory and Practice. A Treatise on Technology and Dispute Resolution. Eleven International Publishing, The Hague (2012)

6. Wooldridge, M.: Foreword. In Ossowski, S. (ed). Agreement Technologies (Law, Governance and Technology Series) pp vii-viii. Springer, Dordrecht (2013)

7. Bellucci, E., Zeleznikow, J.: Developing negotiation decision support systems that support mediators: A case study of the Family Winner system. Artificial Intelligence and Law 13.2, 233 (2005)

8. Comité Européen de Normalisation (CEN), CEN Workshop Agreement: Standardization of Online Dispute Resolution Tools (2009, ICS 03.120.10; Ref. No.: CWA 16026: 2009 E, 2009) $\mathrm{ftp}: / /$ cenftp1.cenorm.be/PUBLIC/CWAs/STANDODR/CWA16026_STANDODR.pdf (Last accessed 25 February 2014)

9. Noriega, P., López de Toro, C.: Towards a Platform for Online Mediation. In Proceedings of the Workshop on Legal and Negotiation Decision Support Systems (LDSS 2009) in conjunction with ICAIL 2009. CEUR Workshop Proceedings CEUR-WS.org/Vol-482/. Barcelona (2009)

10. Casanovas, P., Magre, J., Lauroba., M.E.: Conclusions and Recommendations. In: Casanovas, P., Magre, J., Lauroba, M. E. (eds), Libro Blanco de la Mediación en Catalunya. Huygens, Barcelona (2011)

11. Betts, K.: Lost in translation: Importance of effective communication in online education. Online Journal of Distance Learning Administration 12, 2 (2009)

12. Ekman, P., Friesen, W.V.: Constants across cultures in the face and emotion. Journal of personality and social psychology (1971)

13. Viola, P. Jones, M.: Robust Real-time Object Detection, International Journal of Computer Vision (2001)

14. Ruiz, A., Binefa, X.: Modeling facial expressions dynamics with Gaussian Process Regression. Artificial Intelligence Research and Development, Proceedings of the 15th International Conference of the Catalan Association for Artificial Intelligence (2012).

15. Saragih, J.M., Lucey, S., Cohn, J.F.: Face alignment through subspace constrained meanshifts. Computer Vision, IEEE 12th International Conference (2009).

16. Kanade, K., Cohn, J., Tian, Y.: Comprehensive database for facial expression analysis. Automatic Face and Gesture Recognition (2000).

17. Poblet, M., Suquet, J., Roig, A., González-Conejero, J.: Building Semantic Interoperability for European Civil Proceedings Online. In Contini, F., Lanzara, G.F. (eds), The Circulation of Agency in e-Justice: Interoperability and Infrastructures for European transborder judicial proceedings, pp 287-308. Springer, Dordrecht (2013)

18. Studer, R. Benjamins, VR., Fensel, D.: Knowledge engineering: Principles and methods. Data Knowledge Engineering pp 161. 25.1 (1998)

19. Susskind, R.: Legal informatics - a personal appraisal of context and progress. European Journal of Law and Technology 1, 1 (2010)

20. Poblet, M., Casanovas, P., López Cobo J.L.: The Ontomedia Project: Relational Law, ODR, Multimedia. In: D. Bourcier, P. Casanovas, M. Dulong de Rosnay, C. Maracke (Eds.)Intelligent Multimedia. Managing Creative Works in a Digital World, European Publishing Academic Press, Florence, pp. 349-364 (2010) 
21. Marta Poblet, M., Casanovas, P., López-Cobo, J.L., Casellas, N.: ODR, Ontologies and Web 2.0. Journal of Universal Computer Science, J.UCS, 17, 4 , pp. 618-634 (2011)

22. Poblet, M., Casanovas, P.: Emotions in ODR. The International Review of Law Computers \& Technology, 21, 2 pp. 145-156 (2007)

23. Katsh, E., Rifkin, J.: Online Dispute Resolution: Resolving Conflicts in Cyberspace, Jossey-Bass, San Francisco (2001)

24. Lodder, A.: The Third Party and Beyond. An Analysis of the Different Parties, in particular The Fifth, Involved in Online Dispute Resolution. Information \& Communications Technology Law, 15, 2, June, pp. 143-155 (2013)

25. Lodder, A., Zeleznikow J.: Enhanced Dispute Resolution Through the Use of Information Technology. Cambridge University Press (2010)

26. Carneiro, D., Novais,P., Andrade, F., Zeleznikow, J., Neves, J.: Online dispute resolution: an artificial intelligence perspective. Artificial Intelligence Review 41, 2, pp. 211-240 (2014) 